\title{
Expressão da E-caderina em carcinoma de células escamosas e no tumor de células basais de cães
}

\author{
E-cadherin expression in squamous cell carcinoma and basal cell tumors in dogs
}

\section{Carolina Franchi João ${ }^{\mathrm{I}}$ Mirela Tinucci-CostaII ${ }^{\mathrm{II}}$ Diogo José Cardilli" Joice Lara Maia Faria ${ }^{\mathrm{III}}$ Geórgia Modé Magalhães ${ }^{\mathrm{II}}$ Antonio Carlos Alessi ${ }^{\mathrm{II}}$}

\section{RESUMO}

As caderinas compreendem uma classe de moléculas de adesão celular expressa na superfície de todas as camadas epidérmicas. A E-caderina é a principal caderina envolvida na adesão celular epitelial. A redução de sua expressão está envolvida na progressão de alguns tipos de câncer, no potencial metastático e ainda na definição do prognóstico, principalmente nos carcinomas. O carcinoma de células escamosas e o tumor de células basais são neoplasias cutâneas malignas que afetam os cães. $O$ objetivo deste estudo foi avaliar a expressão da E-caderina no carcinoma de células escamosas $(n=20)$ e no tumor de células basais $(n=15)$, buscando-se relacionar sua expressão ao comportamento biológico desses tumores. Os carcinomas de células escamosas apresentaram significativa redução da expressão da molécula comparado aos tumores de células basais, quando avaliado pelo teste de Fisher $(P=0,0039)$. Também foi observado que células neoplásicas mais diferenciadas apresentaram coloração mais intensa que as menos diferenciadas. Em conclusão, sugere-se que a expressão reduzida da E-caderina em tumores cutâneos pode indicar maior poder infiltrativo $e$ consequentemente mau prognóstico na espécie canina.

Palavras-chave: cães, carcinoma de células escamosas, Ecaderina, imunohistoquímica, neoplasia, tumor de células basais.

\section{ABSTRACT}

The cadherins are a group of cellular adhesion molecules that are expressed on the surface of all epidermic layer. The E-cadherin is the main cadherin involved in epithelial cellular adhesion; the decrease in its expression is related to the progression of some types of cancer, to its metastatic characteristics, and to the prognosis, specially carcinomas. The squamous cell carcinoma and the basal cells tumors are a malignant epithelial neoplasm which affects dogs. The goal of this study was to evaluate E-cadherin's expression in canine tissues that were classified as squamous cell carcinoma or basal cell tumor, and to find a correlation with the biological behavior of the tumors. The squamous cell carcinomas showed significantly decreased expression of the molecule compared to the basal cell tumors when evaluated by Fisher's test $(P=0.0039)$. Also, the more differentiated neoplastic cells had a higher intensity of color than the less differentiated ones. In conclusion, it is suggested that the reduced expression of Ecadherin in skin tumors may indicate greater power infiltrative and consequently poor prognosis in dogs.

Key words: dogs, squamous cell carcinoma, E-cadherin, immunohistochemistry, neoplasia, basal cell tumor.

\section{INTRODUÇÃO}

As caderinas, polipeptídios que representam uma classe de moléculas de adesão (FOTY \& STEINBERG, 2004), conectam uma célula a outra através de uma ligação homofílica dependente do íon cálcio. Associam-se a um grupo de proteínas intracelulares chamadas cateninas, as quais as ligam a microfilamentos actínicos do citoesqueleto e medeiam mecanismos transdutores de sinais que regulam o

\footnotetext{
IUniversidade Federal do Pará (UFPA), Rua Maximino Porpino, 1000, 68740-080, Castanhal, PA, Brasil. Email: carolinafj@ufpa.br. Autor para correspondência.

"Faculdade de Ciências Agrárias e Veterinárias (FCAV), Universidade Estadual Paulista (UNESP), Jaboticabal, SP, Brasil.

III Universidade de Uberaba (UNIUBE), Uberaba, MG, Brasil.
} 
crescimento celular e sua diferenciação (OZAWA \& KEMLER, 1998). As moléculas de adesão clássicas compreendem a E (epithelial)-caderina, $\mathrm{N}$ (neural)caderina e a P (placental)-caderina (FURUKAWA, 1997; FOTY\& STEINBERG, 2004).

A manutenção da arquitetura do tecido adulto depende grandemente da integridade funcional e estrutural das caderinas (ELANGBAM et al., 1997). São consideradas importantes reguladoras da morfogênese em vários órgãos, incluindo a pele. Elas estão envolvidas não somente na manutenção do arranjo dessas células, como na condensação dérmica (HIRAI et al., 1989). Na pele, a E-caderina é expressa na superfície celular de todas as camadas epidérmicas, incluindo os apêndices cutâneos (FUJITA et al., 1992). Ultra-estruturalmente, a E-caderina está distribuída sobre a membrana plasmática dos queratinócitos, mas não na superfície dérmica das células basais. Depósitos densos de E-caderina são encontrados no espaço intercelular dos desmossomos (HORIGUCHI et al., 1994).

Uma disfunção das caderinas pode estar envolvida com várias desordens cutâneas, como doenças bolhosas e comportamento invasivo e metastático dos tumores (FURUKAWA et al., 1997). A principal ação da E-caderina em tumores é a supressão da habilidade de invasão e a ausência desta, associada à progressão tumoral (BEHRENS et al., 1989; NAVARRO et al., 1991; BIRCHMEIER et al., 1993). O dano funcional da E-caderina pode ocorrer por vários mecanismos, mas frequentemente a deleção ou mutação do gene CDH1 estão envolvidos. Alguns estudos mostram que aberrações neste gene são suficientes para predispor o desenvolvimento de tumores malignos. Além disso, mudanças na expressão de proteínas que fazem parte do complexo de adesão da E-caderina também podem prejudicar sua função. A reorganização da cromatina, a hipermetilação e a perda do fator de transcrição coincidem com a supressão da E-caderina em carcinomas (SEMB \& CHRISTOFORI, 1998). De qualquer maneira, a integridade do tecidoé destruída e a célula tumoral fica livre para gerar metástases (GOODSELL, 2002).

O carcinoma de células escamosas (CCE) é uma neoplasia maligna que emerge dos queratinócitos (SCOTT et al., 1996) e corresponde a aproximadamente 5\% dos tumores cutâneos dos cães (THOMAS \& FOX, 1998). Cães de raças de pêlo curto e pele branca ou albina apresentam incidência mais elevada de carcinoma de células escamosas induzido pela luz solar. Esses cães costumeiramente passam muitas horas deitados ao sol (SCOTT et al., 1996). Estes tumores são, geralmente, localmente invasivos e se infiltram na derme e nos tecidos subcutâneos adjacentes, mas lentos para gerar metástases. Apesar disso, há casos relatados sobre a disseminação para linfonodos regionais e pulmão (PULLEY \& STANNARD, 1990; SCOTT et al., 1996; RODASKI \& WERNER, 2009).

Os tumores de células basais (TCB) apresentam crescimento lento e raramente observa-se comportamento agressivo (RODASKI \& WERNER, 2009). São compostos quase exclusivamente por células basais e não exibem evidências de diferenciações de glândulas sebáceas, sudoríparas e de folículos pilosos. Os TCB podem ser classificados histologicamente como sólidos, císticos, adenóides ou medusóides (VAIL \& WITHROW, 1996; THOMAS \& FOX, 1998) e a incidência de recidivas e metástases é baixa (SCOTT et al., 1996; VAIL \& WITHROW, 1996; THOMAS \& FOX, 1998).

Com base nas características descritas desses tumores, buscou-se com este estudo relacionar a expressão da E-caderina com o tipo histológico, grau de diferenciação e comportamento biológico do carcinoma de células escamosas e do tumor de células basais.

\section{MATERIAL E MÉTODOS}

Foram empregadas 35 amostras de tumores cutâneos caninos, incluídas em parafina e classificadas histologicamente como CCE $(n=20)$ e TCB $(n=15)$, segundo os critérios de PULLEY \& STANNARD (1990). As amostras são oriundas do arquivo do Departamento de Patologia Veterinária da Faculdade de Ciências Agrárias e Veterinárias, UNESP, campus de Jaboticabal, da Faculdade de Medicina Veterinária e Zootecnia, UNESP, campus de Botucatu e da Faculdade de Medicina Veterinária, UNESP, campus de Araçatuba.

O método de imunohistoquímica empregado foi o complexo streptoavidina biotina (ABC) desenvolvido por HSU et al. (1981). Cortes de $3 \mu \mathrm{m}$ de espessura foram montados em laminas pré-tratadas com Poly-L-Lisina ${ }^{a}$. As lâminas foram desparafinizadas e reidratadas em baterias de xilóis e alcoois em concentrações decrescentes. Receberam tratamento com solução de metanol e peróxido de hidrogênio $(2,4 \%)$ para bloqueio da peroxidase endógena. Para a recuperação antigênica, ficaram em banho-maria por 40 minutos em solução pré-aquecida a $92^{\circ} \mathrm{C}$ de tampão citrato (pH 6). Depois de resfriados, foram incubados por 30 minutos com Protein Block ${ }^{\mathrm{b}}$ para bloqueio de reações inespecíficas. Em seguida, foram incubados durante a noite a $4^{\circ} \mathrm{C}$ com o anticorpo primário anti-Ecaderina $^{c}$ em câmara úmida. Para detecção da reação imune, foi utilizado o kit $\mathrm{LSAB}^{\mathrm{d}}$, por 30 minutos. As reações foram reveladas pelo substrato cromogênico 
3,3 diaminobenzidina ${ }^{\mathrm{e}}$, contracorados pela hematoxilina de Harris por um minuto, e então lavados em água corrente.

Como controle positivo, além das áreas de epitélio normal dos próprios espécimes, foi utilizado útero canino, que sabidamente expressa a E-caderina em sua camada epitelial. Como controles negativo, o anticorpo primário anti-E-caderina foi substituído por tampão PBS, pH 7,2; e por imunoglobulina $\mathrm{G}$ de camundongo.

Para avaliação dos resultados, foram consideradas como expressões conservadas de Ecaderina as marcações de coloração moderada a intensa em mais de 75\% das células neoplásicas. Expressões inferiores a $75 \%$ foram consideradas reduzidas, seguindo os critérios empregados por BRUNETTI et al. (2005). As observações foram feitas em microscópio óptico comum por dois observadores e os resultados foram então estabelecidos.

O teste exato de Fisher foi utilizado para comparar a expressão da E-caderina entre o carcinoma de células escamosas e o tumor de células basais, através do programa $\mathrm{SAS}^{\mathrm{f}}$.

\section{RESULTADOS E DISCUSSÃO}

Setenta por cento $(n=14)$ dos CCEs apresentaram expressão da E-caderina reduzida. Seis amostras (30\%) tiveram a expressão conservada da molécula (Figura 1), sendo cinco delas carcinomas queratinizados e uma carcinoma não queratinizado.
Exemplos de marcação preservada e reduzida no CCE estão apresentados na figura 2 (2A e 2B). Observou-se também que a expressão da E-caderina apresentou diferentes intensidades de coloração de acordo com o grau de diferenciação das células, em que células mais diferenciadas apresentavam coloração mais intensa (Figura 2C).

O TCB apresentou comportamento inverso ao do CCE. Oitenta por cento $(n=12)$ das amostras apresentaram expressão E-caderina em mais de 75\% das células. Em três amostras (20\%), a expressão estava reduzida (Figura 1). Dos TCB, 20\% eram do tipo medusóide (3), 53,3\% adenóide (8) e 26,7\% sólido (4). Apenas uma amostra de cada tipo não apresentou expressão conservada de E-caderina. Exemplo de marcação preservada no TCB está apresentado na figura 2D.

A diferença da expressão da E-caderina no CCE e TCB foi significativa pelo teste de Fisher $(\mathrm{P}=0,0039)$ a $1 \%$ de significância. Embora não se tenha encontrado estudos prévios dessa molécula em CCE e TCB de cães, estudos em tumores mamários caninos mostraram correlação positiva entre a diminuição da expressão da E-caderina e o aumento do seu poder de invasão. Em carcinomas mamários de maior malignidade, houve redução significativa da expressão de E-caderina, enquanto que aqueles de menor grau de malignidade apresentaram expressão conservada dessa molécula. Também relacionaram a redução de expressão com aumento de tamanho, presença de ulceração, metástases em linfonodos, necrose e comportamento

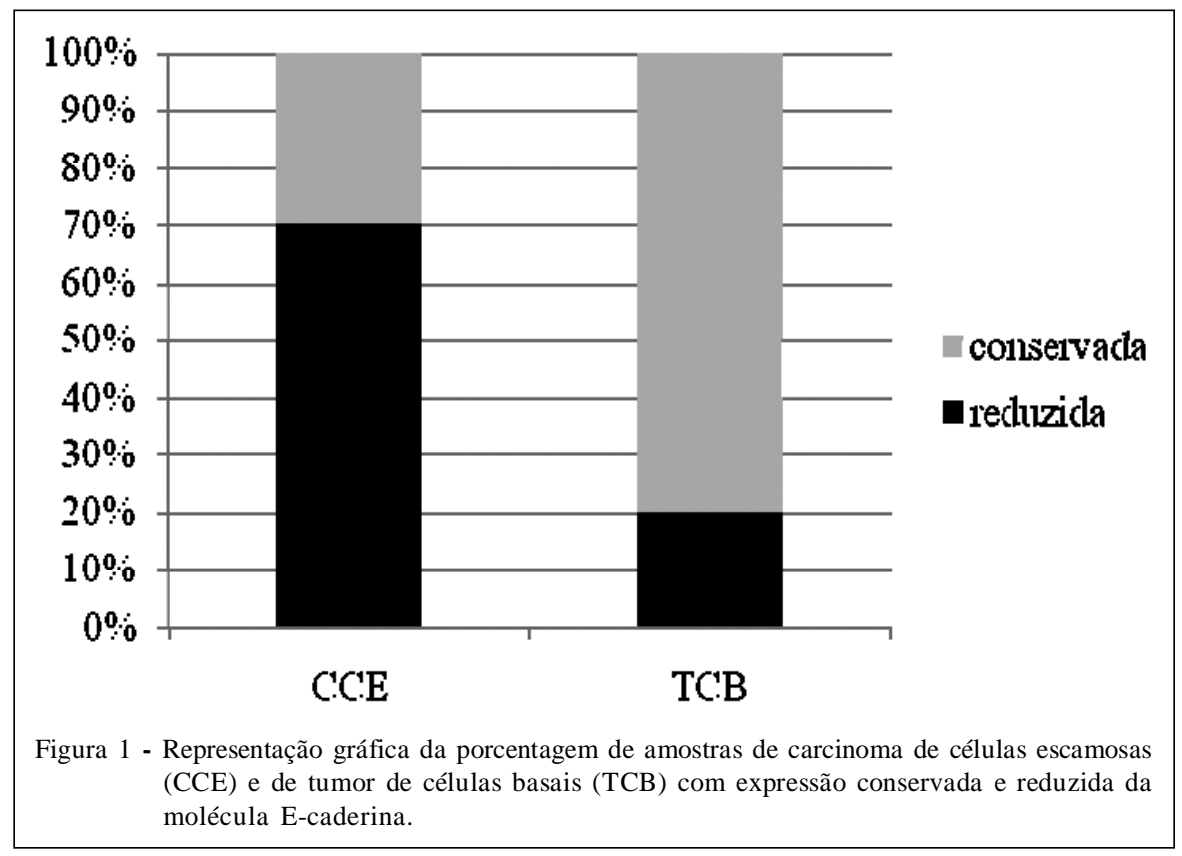

Ciência Rural, v.41, n.9, set, 2011. 


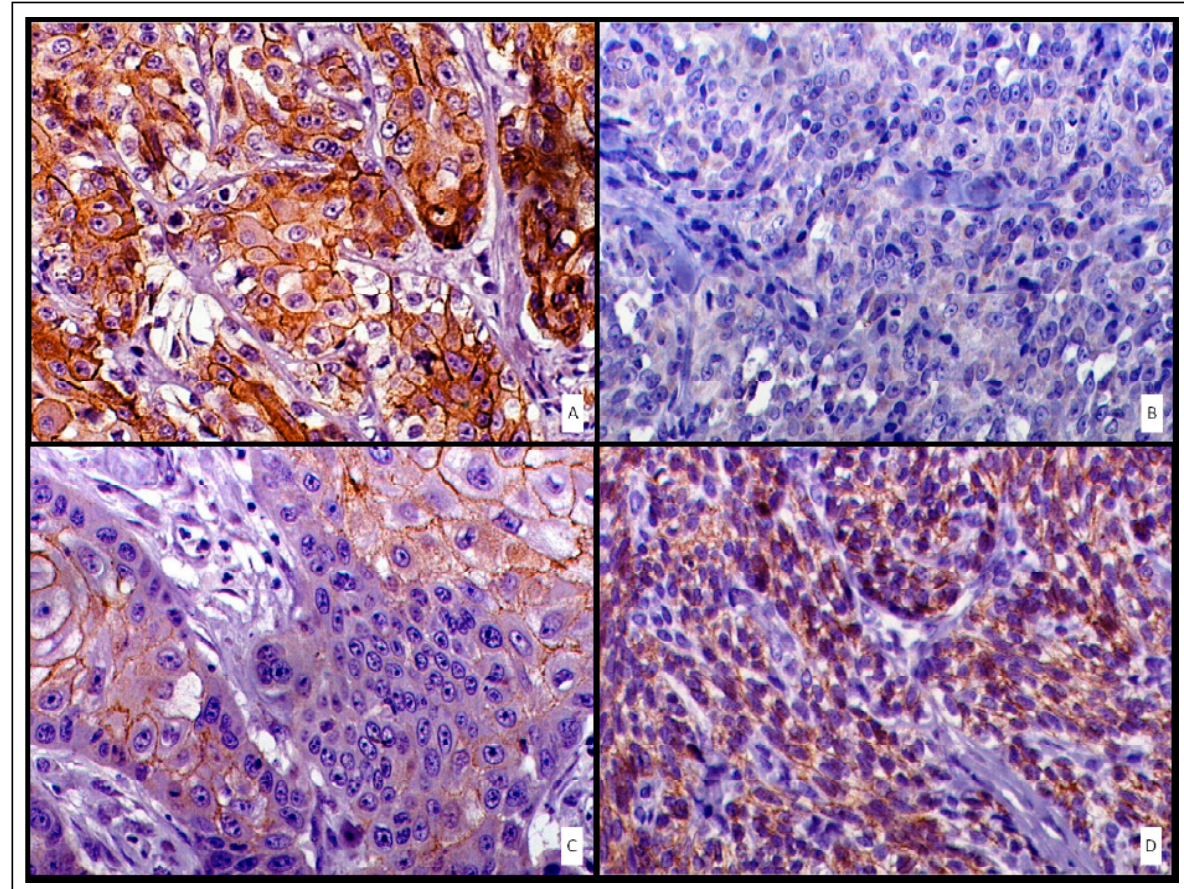

Figura 2 - Preparações imunohistoquímicas método $\mathrm{ABC}$, contracorado pela hematoxilina de Harris. Aumento 400x. 2A: carcinoma de células escamosas queratinizado com expressão conservada de E-caderina (mais de $75 \%$ de células neoplásicas marcadas com coloração castanha). 2B: carcinoma de células escamosas não queratinizado com expressão reduzida de E-caderina (menos de 75\% de células neoplásicas marcadas). 2C: carcinoma de células escamosas do tipo queratinizado exibindo diferentes padrões de marcação pelo anticorpo anti E-caderina, onde se observa coloração mais intensa em células neoplásicas mais diferenciadas em relação às menos diferenciadas. 2D: tumor de células basais tipo adenóide com expressão conservada de E-caderina.

infiltrativo do tumor, sem, contudo, associarem ao grau histológico (BRUNETTI et al., 2005; MATOS et al., 2006; PIEKARZet al., 2008).

Em tumores cutâneos humanos, a redução da expressão de E-caderina também foi relacionada com o poder invasivo e metastático desses tumores (SCHIPPER, 1991; FURUKAWA et al., 1997). No câncer colorretal humano, a redução da expressão da Ecaderina indica mau prognóstico, sendo correlacionada com o aumento da invasividade tumoral, desenvolvimento de sítios metastáticos e menor taxa de sobrevida (KWAK et al., 2007).

O rompimento da adesão célula-célula durante a carcinogênese é a base para a invasão e metástase (BATLLE et al., 2000; POLAKIS, 2007; GLOUSHANKOVA, 2008). AE-caderina é uma molécula de adesão celular responsável pela manutenção da integridade do tecido e por suprimir a habilidade de invasão das células tumorais (BEHRENS et al., 1989; NAVARRO et al., 1991; BIRCHMEIER et al., 1993). Sendo assim, a perda dessa molécula no tecido neoplásico poderia interferir diretamente na liberação de células tumorais, aumentando o poder de invasão e a chance de formação de metástases.

Neste estudo, a deficiente expressão da Ecaderina nos CCEs pode indicar que esse tumor apresenta menor adesão entre as células, com maior potencial infiltrativo e de invasão dos tecidos adjacentes, apresentando comportamento mais agressivo nos cães, quando comparado aos TCBs. Esse resultado é condizente com o comportamento biológico desses tumores descrito na literatura, em que o CCE apresenta um comportamento mais agressivo que o TCB, principalmente pelo seu poder infiltrativo (THOMAS \& FOX, 1998). Portanto, a redução da expressão da E-caderina nos CCEs pode ter relação com o comportamento tumoral, podendo ser utilizada na definição de um prognóstico.

\section{CONCLUSÃO}

Com base nos resultados deste estudo, sugere-se que a expressão reduzida da E-caderina em tumores cutâneos pode indicar maior poder infiltrativoe consequentemente mau prognóstico na espécie canina. 


\section{AGRADECIMENTOS}

Os autores agradecem aos professores $\operatorname{Dr}^{\mathrm{a}}$ Reneé L. Amorim, da Faculdade de Medicina Veterinária e Zootecnia da UNESP, campus de Botucatu e Dr ${ }^{a}$ Gisele F. Machado da Faculdade de Odontologia da UNESP, campus de Araçatuba pela doação de amostras para a realização deste trabalho. Esta pesquisa foi financiada pela Fundação de Amparo à Pesquisa do Estado de São Paulo (FAPESP).

\section{COMITE DE ÉTICA E BIOSSEGURANÇA}

Trabalho aprovado pela Comissão de ética no uso de animais (CEUA), Faculdade de Ciências Agrárias e Veterinárias (FCAV), Universidade Estadual Paulista (UNESP) de Jaboticabal sob protocolo n.008410.

\section{FONTES DE AQUISIÇÃO}

a- Poly-L-Lisina (cód. P4832 - Sigma Chemical Co., St. Louis, MO EUA)

b- Protein Block (DakoCytomation, Ref. X0909)

c- Anticorpo monoclonal anti-E-caderina (camundongo antihumano, Zymed Laboratories Inc.,clone 4A2C7)

d- LSAB (Sistema de Detecção Ultra Estreptavidina Universal, DakoCytomation, Ref. K0690)

e- DAB (Cód. SK-4100 - DAB Vector Laboratóries, Burlingame, CA, EUA)

f- SAS (9.1, SAS Institute, Cary, NC, USA).

\section{REFERÊNCIAS}

BATLLE, E. et al. The transcription factor Snail is a repressor of E-cadherin gene expression in epithelial tumour cells. Nat Cell Biol, v.2, p.84-89, 2000. Disponível em: <http:// www.lsic.ucla.edu/classes/mimg/temp/old229/raj_batlle.pdf>. Acesso em: 13 abr. 2011. doi: 10.1038/35000034.

BEHRENS, J. et al. Dissecting tumor cell invasion: epithelial cells acquire invasive properties after the loss of uvomorulinmediated cell-cell adhesion. J Cell Biol, v.108, p.2435-2447, 1989. Disponível em: <http://jcb.rupress.org/content/108/6/ 2435.full.pdf $>$. Acesso em: 13 abr. 2011. doi: 10.1083/ jcb.108.6.2435.

BIRCHMEIER et al. Molecular mechanisms leading to cell junction (cadherin) deficiency in invasive carcinomas. Semin Cancer Biol, v.4, p.231-239, 1993.

BRUNETTI, B. et al. E-Cadherin and â-catenin reduction influence invasion but not proliferation and survival in canine malignant mammary tumors. Vet Pathol, v.42, p.781-787, 2005. Disponível em: <http://vet.sagepub.com/content/42/6/ 781.full.pdf + html>. Acesso em: 13 abr. 2011. doi: 10.1354/ vp.42-6-781.

ELANGBAM, C.S. et al. Cell adhesion molecules- Update. Vet Pathol, v.34, p.61-73, 1997. Disponível em: <http:// vet.sagepub.com/content/34/1/61.full.pdf + html $>$. Acesso em: 13 abr. 2011. doi: 10.1177/030098589703400113.

FOTY, R.A.; STEINBERG, M.S. Cadherin-mediated cell-cell adhesion and tissue segregation in relation to malignancy. Int J Dev Biol, v.48, p.397-409, 2004. Disponível em: <http:// www.ijdb.ehu.es/web/paper.php?doi=10.1387/ijdb.041810rf $>$. Acesso em: 13 abr. 2011. doi: 10.1387/ijdb.041810rf.
FUJITA, M. et al. Expression of cadherin cell adhesion molecules during human skin development: morphogenesis of epidermis, hair follicles and sweat ducts. Arch Dermatol Res, v.284, p.159-166, 1992.

FURUKAWA, F. et al. Roles of E- and P-cadherin in the human skin. Microscopy Res Technique, v.38, p.343-352, 1997.

GLOUSHANKOVA, N.A. Changes in regulation of cell-cell adhesion during tumor transformation. Biokhimiia, v.73, p.742750, 2008. Disponível em: <http://www.springerlink.com/ content/b3260152038743u5/fulltext.pdf>. Acesso em: 13 abr. 2011. doi: $10.1134 / \mathrm{S} 000629790807002 \mathrm{X}$.

GOODSELL, D.S. The molecular perspective: cadherin. Oncologist, v.7, p.467-468, 2002.

HIRAI, Y. et al. Expression and role E-and P-cadherin adhesion molecules in embryonic histogenesis. II skin morphogenesis. Development, v.105, p.271-277, 1989.

HORIGUCHI, Y. et al. Ultrastrutural localization of E-cadherin cell adhesio molecule on the cytoplasmic membrane of keratinocytes in vivo and in vitro. J Histochem Cytochem, v.42, p.1333-1340, 1994. Disponível em: <http://jhc.sagepub.com/ content/42/10/1333.full.pdf+html>. Acesso em: 13 abr. 2011. doi: $10.1177 / 42.10 .7930515$.

HSU, S.M. et al. A comparative study of the peroxidaseantiperoxidades method and an avidin biotin complex method for studying polypeptide hormones with radioimmununoassay antibodies. Am J Clin Pathol, v.75, p.734-738, 1981.

KWAK, J.M. et al. The prognostic significance of E-cadherin and liver intestine-cadherin expression in colorectal cancer. Dis Colon Rectum, v.50, p.1873-1880, 2007. Disponível em: <http://www.springerlink.com/content/0q34lpg57gt37737/ fulltext.pdf $>$. Acesso em: 13 abr. 2011. doi: 10.1007/s10350007-9034-1.

MATOS, A.J.F. et al. E-cadherin expression in canine malignant mammary tumours: relationship to other clinico-pathological variables. J Comp Pathol, v.134, p.182-189, 2006. Disponível em: $<\mathrm{h} \mathrm{t} \mathrm{t} \mathrm{p} \mathrm{:} \mathrm{//} \mathrm{w} \mathrm{w} \mathrm{w.} \mathrm{s} \mathrm{c} \mathrm{i} \mathrm{e} \mathrm{n} \mathrm{c} \mathrm{e} \mathrm{d} \mathrm{i} \mathrm{r} \mathrm{e} \mathrm{c} \mathrm{t.} \mathrm{c} \mathrm{o} \mathrm{m} \mathrm{/}$ science?_ob=MImg\&_imagek ey=B 6WHW-4JHMJX0 - 1 5\&_cdi=6861\&_user=972052\&_pii=S0021997505001222\&_orig in $=$ gateway\&_coverDate $=04 \% 2 F 30 \% 2 F 2006 \& \_s k=998659997 \&$ vie $\mathrm{w}=\mathrm{c} \& w c h p=\mathrm{dGLzVzbzSkzV} \& \mathrm{md} 5=8 \mathrm{ab} 1 \mathrm{a} 308298115 \mathrm{bf} 31 \mathrm{~b} 02 \mathrm{~b} 00016$ e4d58\&ie=/sdarticle.pdf $>$. Acesso em: 13 abr. 2011. doi: 10.1016/ j.jcpa.2005.10.004

NAVARRO, P. et al. A role for the E-cadherin cell-cell adhesion molecule during tumor progression of mouse epidermal carcinogenesis. J Cell Biol, v.115, p.517-533, 1991. Disponível em: <http://jcb.rupress.org/content/115/2/517.full.pdf+html>. Acesso em: 13 abr. 2011. doi: 10.1083/jcb.115.2.517.

OZAWA, M.; KEMLER, R. Altered cell adhesion activity by pervanadate due to the dissociation of alpha-cadhenin.catenin complex. J Biol Chem, v.273, p.6166-6170, 1998. Disponível em: <http://www.jbc.org/content/273/11/6166.full.pdf+html>. Acesso em: 13 abr. 2011. doi: 10.1074/jbc.273.11.6166. 
PIEKARZ, C.H. et al. Expressão das caderinas nos tumores mamários em cadelas. Arch Vet Sci, v.13, p.13-21, 2008.

POLAKIS, P. The many ways of Wnt in cancer. Curr Opin Genet Dev, v.17, p.45-51, 2007. Disponível em: < h t t p : / / w w w . s c i e n c e d i r e c t . c o m / science?_ob=MImg\&_imagekey=B6VS0-4MRNCM9-3$1 \&$ \&cdi=6248\&_user=972052\&_pii=S0959437X06002413\&_o rigin $=$ gateway \&_coverDate $=02 \% 2$ F28\%2F2007\&_sk $=999829$ $998 \& \mathrm{v}$ i e w $=\mathrm{c} \& \mathrm{w} \mathrm{c} \mathrm{h} \mathrm{p}=\mathrm{d} \mathrm{G} \mathrm{L} \mathrm{b} \mathrm{V} \mathrm{t} \mathrm{b} \mathrm{-}$ zSkzV\&md5 =f00436234f74f79ea8786bec5baa6024\&ie $=/$ sdarticle.pdf $>$. Acesso em: 13 abr. 2011. doi: 10.1016/ j.gde.2006.12.007.

PULLEY, T.; STANNARD, A.A. Tumour of the skin and soft tissues. In: MOULTON, J.E. Tumors in domestic animals. 3.ed. Los Angeles: Library of Congress, 1990. p.56-61.

RODASKI, S.; WERNER, J. Neoplasias da pele. In: DALECK, C.R. et al. Oncologia em cães e gatos. São Paulo: Roca, 2009. p.253-280.
SCHIPPER, J.H. E-cadherin expression in squamous cell carcinoma of head and neck: inverse correlation with tumour dedifferentiation an lymph nod metastasis. Cancer Res, v.51, p.6328-6337, 1991.

SCOTT, D.W. et al. In: SCOTT, D.W. et al. Dermatologia de pequenos animais. 5.ed. Rio de Janeiro: Interlivros, 1996. p.448-451.

SEMB, H.; CHRISTOFORI, G. The tumor-suppressor function of E-cadherin. Am J Hum Genet, v.63, p.1588-1593, 1998.

THOMAS, R.C.; FOX, L.E. Tumors of the skin and subcutis. In: MORRISON, W.B. Cancer in dogs and cats. Baltimore: Williams \& Wilkins, 1998. p.489-510.

VAIL, M.D.; WITHROW, S.J. Tumors of the skin and subcutaneous tissues. In: WITHROW, S.J.; MACEWEN, E.G. Small animal clinical oncology. 2.ed. Philadelphia: Saunders, 1996. p.173-176. 